\title{
Improvement of myocardial contractility in a porcine model of chronic ischemia using a combined transmyocardial revascularization and gene therapy approach
}

Keith A. Horvath, MD, ${ }^{\text {a }}$ Chia Yang J. Lu, MD, ${ }^{a}$ Emmanuel Robert, MS, ${ }^{a}$ Glenn F. Pierce, PhD, ${ }^{b}$ Rodney Greene, BS, ${ }^{a}$ Barbara A. Sosnowski, $\mathrm{PhD}^{\mathrm{b}}$ and John Doukas, $\mathrm{PhD}^{\mathrm{b}}$

From the Northwestern University, Feinberg School of Medicine, ${ }^{\text {a }}$ Chicago, Ill; and Selective Genetics Inc, San Diego, Calif. ${ }^{\text {b }}$

The research presented here was funded in part by the American Heart Association grant $0030271 \mathrm{~N}$. Adenoviral vector for FGF2 and matrix was provided by Selective Genetics Inc, San Diego, Calif.

Received for publication July 21, 2004; revisions received Oct 14, 2004; accepted for publication Oct 27, 2004

Address for reprints: Keith A. Horvath, MD, Chief, Cardiothoracic Surgery Branch, National Heart, Lung, and Blood Institute, NIH, Building 10, Room 8C103, 10 Center Dr, MSC 1754, Bethesda, MD 20892 (Email: horvathka@mail.nih.gov).

J Thorac Cardiovasc Surg 2005;129:1071-7 $0022-5223 / \$ 30.00$

Copyright (C) 2005 by The American Association for Thoracic Surgery

doi:10.1016/j.jtcvs.2004.10.017
Objectives: The purpose of this study was to investigate whether a novel fibroblast growth factor- 2 gene formulation, providing a localized and sustained availability of the adenoviral vector from a collagen-based matrix, in combination with $\mathrm{CO}_{2}$ transmyocardial laser revascularization would lead to an enhanced angiogenic response and improved myocardial function.

Methods: Fibroblast growth factor-2 gene was delivered by means of an adenoviral vector (adenoviral fibroblast growth factor-2) formulated in a collagen-based matrix. The ischemic areas of 33 animals were then treated. Group 1 was treated with $\mathrm{CO}_{2}$ transmyocardial laser revascularization; group 2 was treated with intramyocardial injections of adenoviral fibroblast growth factor-2 in a collagen-based matrix; group 3 had a combination treatment of matrix adenoviral fibroblast growth factor-2 and $\mathrm{CO}_{2}$ transmyocardial laser revascularization; and group 4 received injections with saline-formulated adenoviral fibroblast growth factor-2. Baseline left ventricular function was assessed by echocardiography and cine magnetic resonance imaging. Studies were repeated 6 weeks after treatment. Vascular development was assessed using anti- $\alpha$-actin immunohistochemistry.

Results: Matrix adenoviral fibroblast growth factor- $2+$ transmyocardial laser revascularization-treated areas had a $105 \%$ increase in arteriolar development versus either treatment alone $(P<.05)$ and a $390 \%$ increase compared with saline-formulated adenoviral fibroblast growth factor-2 treatment alone $(P<$ $.05)$. Contractility was significantly improved in matrix adenoviral fibroblast growth factor- $2+$ transmyocardial laser revascularization-treated areas as measured by myocardial wall thickening. This functional improvement was confirmed by cine magnetic resonance imaging, in which a $90 \%$ increase in the contractility of the treated segments was demonstrated after matrix adenoviral fibroblast growth factor- $2+$ transmyocardial laser revascularation. The other treatments provided significantly less restoration of myocardial function.

Conclusions: The increase in angiogenesis as a result of matrix adenoviral fibroblast growth factor-2 gene therapy in combination with $\mathrm{CO}_{2}$ transmyocardial laser revascularization is greater than that seen in either therapy alone. A concomitant improvement in myocardial function was seen as a result of this angiogenic response.

$\mathrm{T}$ he majority of patients who require intervention for their coronary artery disease can be adequately treated by percutaneous coronary interventions or coronary artery bypass grafting. However, a major reason for failure of these treatments is their dependency on luminal size and coronary outflow. Methods to 
stimulate myocardial neovascularization that is not dependent on vessel caliber therefore provide an important alternative treatment. Numerous experimental and clinical studies have evaluated gene therapy as a treatment for ischemic heart disease. ${ }^{1-11}$ In addition, transmyocardial laser revascularization (TMR) has been developed to treat end-stage coronary artery disease. ${ }^{12-20}$ As with gene therapy, TMR's principal mechanism of action seems to be stimulation of neovascularization. ${ }^{21-27}$ Additional laboratory work indicates that combined therapy may be synergistic. ${ }^{28,29} \mathrm{We}$ have previously reported the successful use of a novel gene delivery method, ${ }^{30,31}$ in which an adenoviral (Ad) vector is formulated in a collagen-based matrix (termed a "geneactivated matrix" [GAM]). The advantages of this approach include improved vector retention at delivery sites and the early deposition of a provisional matrix favorable for tissue remodeling and neovascularization. We have also reported the positive influence of $\mathrm{CO}_{2}$ TMR on treating ischemic myocardium (including angiogenesis) and subsequent functional outcome. ${ }^{25,26,32}$ This study determines whether the combination of a GAM and $\mathrm{CO}_{2}$ TMR would lead to an additive improvement in either neovascularization or left ventricular function of chronically ischemic myocardium.

\section{Materials and Methods \\ Animal Model}

Animals received humane care as approved by the Center for Experimental Animal Research at Northwestern University and in compliance with the "Guide for the Care and Use of Laboratory Animals" published by the National Institutes of Health (publication 85-23, revised 1985).

\section{Operative Technique}

In an effort to recreate the clinical situation, we used a standard animal model of chronic myocardial ischemia. ${ }^{33,34}$ Thirty-six Yorkshire pigs, weighing 12 to $15 \mathrm{~kg}$, were anesthetized with tiletamine hydrochloride (Telazol; $10 \mathrm{mg} / \mathrm{kg}$ ), xylazine $(0.25 \mathrm{mg} /$ $\mathrm{kg}$ ), and atropine $(2 \mathrm{mg})$ intramuscularly, followed by sodium thiamylal $(2.5 \%, 10 \mathrm{mg} / \mathrm{kg})$ intravenously. After intubation, maintenance anesthesia was maintained with isoflurane (Abbott Laboratories, Chicago, Ill). Before exposure of the heart, lidocaine (1 $\mathrm{mg} / \mathrm{kg}$ ) was administered intravenously. The same anesthetic regimen was used for each for the 3 different surgical procedures that were performed.

At the initial operation, with sterile technique, the heart was exposed through a small left thoracotomy, and the pericardium was opened. The proximal left circumflex artery was dissected free, and an ameroid constrictor (Research Instruments Manufacturing, Corvallis, Ore) with an internal diameter of $2.5 \mathrm{~mm}$ was placed in the same location for each animal, specifically around the origin of the left circumflex artery. The pericardium and chest were then closed. The animals were allowed to recover and were ambulatory before leaving the operating room suite. They were monitored daily by a veterinarian and his staff as well as the surgical team. Adequate food and water were provided, and intake and weights were measured daily. Antibiotics were administered intramuscu- larly for 3 days postoperatively. Pain medications were also given intramuscularly until the animals were ambulating without difficulty and exhibiting normal activity levels.

Five weeks later, to evaluate the baseline regional contractility and the precise areas of hypoperfusion versus infarction, contrastenhanced and cine magnetic resonance imaging (MRI) were performed. While anesthetized, the animals were scanned on a 1.5-T Siemens Symphony Scanner (Siemens Medical Systems, Erlangen, Germany). Short-axis images every $10 \mathrm{~mm}$ were performed to cover the entire left ventricular volume. Cine MRI provided evaluation of regional myocardial contractility, and contrast-enhanced MRI provided information on the presence of any regional myocardial injury. Animals received a routine clinically approved contrast agent intravenously (Magnevist, Abbott Laboratories; 0.2 $\mathrm{mmol} \cdot \mathrm{kg} \cdot \mathrm{wt}$; maximum rate of $10 \mathrm{~mL} / 15 \mathrm{sec})$. At least 5 minutes were allowed for the contrast to circulate, and then MRI was performed at each of the cine short-axis locations.

After these studies, a second operation was performed through a larger left thoracotomy in which the pericardium was reopened and the heart was reexposed. Blood pressure and electrocardiographic monitoring were used. Rest and dobutamine stress epicardial echocardiography (7.5 MHz: model 128; Acuson Inc, Mountain View, Calif) were performed to provide an assessment of the viability of the myocardium and a method of determining the extent of the ischemia. Dobutamine was administered intravenously starting at $5 \mu \mathrm{g} \cdot \mathrm{kg} \cdot \mathrm{min}$ and titrated to a maximum infusion rate of $50 \mu \mathrm{g} \cdot \mathrm{kg} \cdot \min$ to achieve a $100 \%$ increase in the resting heart rate. There were no significant differences in resting heart rates at operations 2 and $3(96 \pm 18$ vs $88 \pm 16, P=.8)$ or between stress heart rates at operations 2 and 3 (194 \pm 27 vs 181 $\pm 21, P=.6$ ). Similarly, mean arterial pressures demonstrated a modest increase with stress but with no significant differences between the resting and stress blood pressure measurements for operations 2 and 3 .

Two animals died after ameroid placement and before randomization. The remaining animals were then randomized into 1 of 4 groups at operation 2. Group 1: The ischemic area was treated with $\mathrm{CO}_{2}$ TMR (20 channels, $\mathrm{n}=8$ ). Group 2: The ischemic area was treated with intramyocardial GAM (20 injections, $\mathrm{n}=8$ ). The GAM consisted of an adenovirus encoding the gene for human fibroblast growth factor (FGF)2 (18 kD form) (AdFGF2) formulated in a matrix of $1 \%$ bovine collagen and $1 \%$ bovine gelatin. ${ }^{32}$ A 27-gauge needle was used to deliver GAM into the ischemic region as 20 injections of $100 \mu \mathrm{L}$ volume each $\left(5 \times 10^{10}\right.$ viral particles/injection) were placed as 1 injection per square centimeter of tissue. Group 3: A combination treatment of $\mathrm{CO}_{2}$ TMR and GAM was administered; GAM was directly injected into TMR channels (20 channels with 20 injections, 1 per channel, $\mathrm{n}=10$ ). Group 4: Treatment with identical intramyocardial injections with saline-formulated AdFGF2 (20 injections, $\mathrm{n}=7$ ) was administered. The thoracotomies were then closed, and the animals were allowed to recover. The aforementioned postoperative care was then reinstituted. At the time of sacrifice (operation no. 3) 6 weeks later, the animals underwent a repeat thoracotomy. At that time, they underwent repeat rest and dobutamine stress echocardiography and repeat contrast-enhanced and cine MRI. The animals were then sacrificed, and the hearts were harvested for histologic anal- 
ysis. After explantation, confirmation of occlusion of the circumflex artery by the ameroid constrictor was performed.

\section{Echocardiographic Analysis}

The echocardiographic images were recorded on a half-inch videotape. End-diastolic and end-systolic images were then digitized off-line from the videotape with a dedicated software package (Prism Lite for Windows, Version 5.14; Tomtec Imaging Systems, Broomfield, Colo). The digitized images were spatially calibrated, and the endocardial and epicardial contours were traced. The software then automatically calculated the wall motion along the 100 evenly distributed lines of site around the contour. By standard segmental contraction analysis, the mean wall motion score for each segment was obtained (48 segments for each short-axis image). Segmental contraction was defined as the change in wall thickness between systole and diastole as measured in centimeters. Echocardiographic analysis was performed by an independent observer blinded to the treatment that the animals received. Segmental contraction was compared in all segments at all times using each animal as its own control. As an additional control, the historical data from untreated animals were compared with those of the gene therapy-treated animals.

\section{Magnetic Resonance Imaging Analysis}

Regional contractility, as measured by wall thickening, was determined with commercial software (ARGUS, Siemens Medical Systems) in 72 segments for each animal by the modified centerline method. The measurements were performed from short-axis images at the midpapillary region of the left ventricle, as well as 1 image above $(10 \mathrm{~mm})$ and 1 image below $(10 \mathrm{~mm})$ this region. With contrast enhancement, areas with an infarction appear to be hyperenhanced. Assessment of the degree of hyperenhancement when present was performed by outlining only the hyperenhanced region of each segment. The percent infarction was then calculated on the basis of the outlined area of hyperenhancement compared with the total area of each segment.

\section{Histologic Analysis}

Tissue samples were fixed with $4 \%$ paraformaldehyde in Sörenson's phosphate and processed as paraffin-embedded sections. For routine histochemistry, sections were stained with hematoxylineosin and Mallory's trichrome. Immunohistochemistry was also performed to detect $\alpha$-actin expression by smooth muscle cells. In brief, anti- $\alpha$-actin clone 1A4 (Dako, Carpinteria, Calif) was used as a primary antibody, horseradish peroxidase-conjugated antimouse immunoglobulin $\mathrm{G}$ as a secondary antibody (Vector Laboratories, Burlingame, Calif), and 3,3'-diaminobenzidine (DAB) as a detection agent.

The techniques used for morphometric analyses have been described and entail measurements throughout the entire left ventricle. $^{26,27}$ This method, in which muscular wall areas are measured, was selected over direct measurement of vessel size as being more accurate (measurement of vessel size requires perfusion fixation at the proper pressure to prevent vessel distortion or collapse). ${ }^{30,31}$ Immunostained paraffin sections taken from nonischemic and ischemic areas of the heart $(n=4$ per animal) were first photographed by a blinded observer as nonoverlapping microscopic fields $(40 \times$ total magnification), so the entire section was captured. An image analysis software package (Image-Pro Plus, Media Cybernetics, Silver Spring, Md) was then used to score individual pixels in these images as DAB positive or negative, based on a mask set to recognize all DAB positive cells but corrected for the background staining (ie, myocardium free of visible muscular arterioles). The program then converted pixel measurements into an area measurement, and the highest 6 data values for each section (representing the areas densest in arterioles) were grouped. These data are presented as the total arteriole wall area (in cubic millimeters) per microscopic field.

\section{Statistical Analysis}

All results are presented as mean \pm SD. One-way analysis of variance was used to compare differences in arteriogenesis and contractility between the 4 groups. Paired $t$ tests were performed when appropriate for comparison with baseline data. Bonferroni correction was used for multiple comparisons. All statistical tests were 2-tailed.

\section{Results}

In addition to the aforementioned animals that died before randomization, 1 animal was noted to have significant myocardial infarction just before randomization, based on hyperenhancement seen on MRI. This animal was therefore excluded. There were no significant resting hemodynamic or electrocardiographic differences between the animals at the second and third operations. In addition, all animals underwent the same degree of dobutamine stress at each operation.

Myocardial function, as assessed by echocardiographic measurements of the segmental contraction (Figure 1), revealed hypokinesis of the ischemic zone after placement of the ameroid constrictor; there was no change, however, in the segmental contractions in the nonischemic zone (data not shown). There were also no significant differences in the baseline resting function between groups, and these measurements were consistent with previous controls. ${ }^{32}$ The posttreatment resting function of the ischemic zone, however, showed a significant improvement for all groups, with the greatest improvements being seen in the TMR- and/or GAM-treated groups (73\%-101\% improvement). Animals treated with saline-formulated AdFGF2 by comparison had relatively modest improvements (24\%).

Further confirmation of this posttreatment functional improvement was obtained by cine MRI (Figure 2). Although function was improved for all treatment groups, the most significant improvement was seen in the animals treated with the combination of the GAM and $\mathrm{CO}_{2}$ TMR. Of the 216 segments in the treated area, 112 segments (52\%) demonstrated improvement in contractility after $\mathrm{CO}_{2}$ TMR alone; 110 segments (51\%) showed improvement after GAM alone, and 192 segments (89\%) demonstrated improved contractility after treatment with the combination of $\mathrm{GAM}+\mathrm{CO}_{2}$ TMR $\left(P=.001, \mathrm{GAM}+\mathrm{CO}_{2}\right.$ TMR vs GAM or $\mathrm{CO}_{2} \mathrm{TMR}$ alone). In contrast, only 13 of the segments 


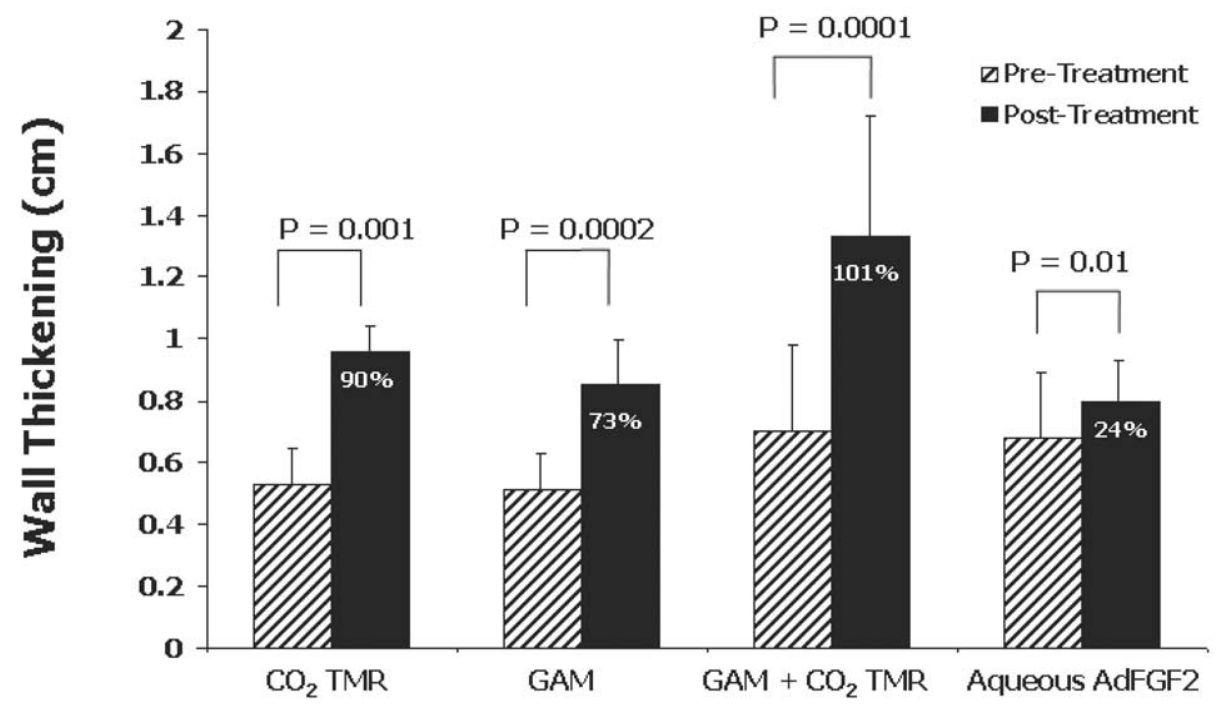

\section{Treatment Groups}

Figure 1. Contractility as assessed by echocardiography. Resting echo shows the increase of wall thickening in the ischemic zone after treatment. The percentages in the posttreatment bars are improvement compared with pretreatment. The matrix adenoviral fibroblast growth factor (AdFGF2) $+\mathrm{CO}_{2}$ transmyocardial laser revascularization (TMR)-treated group had the most significant improvement compared with the other groups.

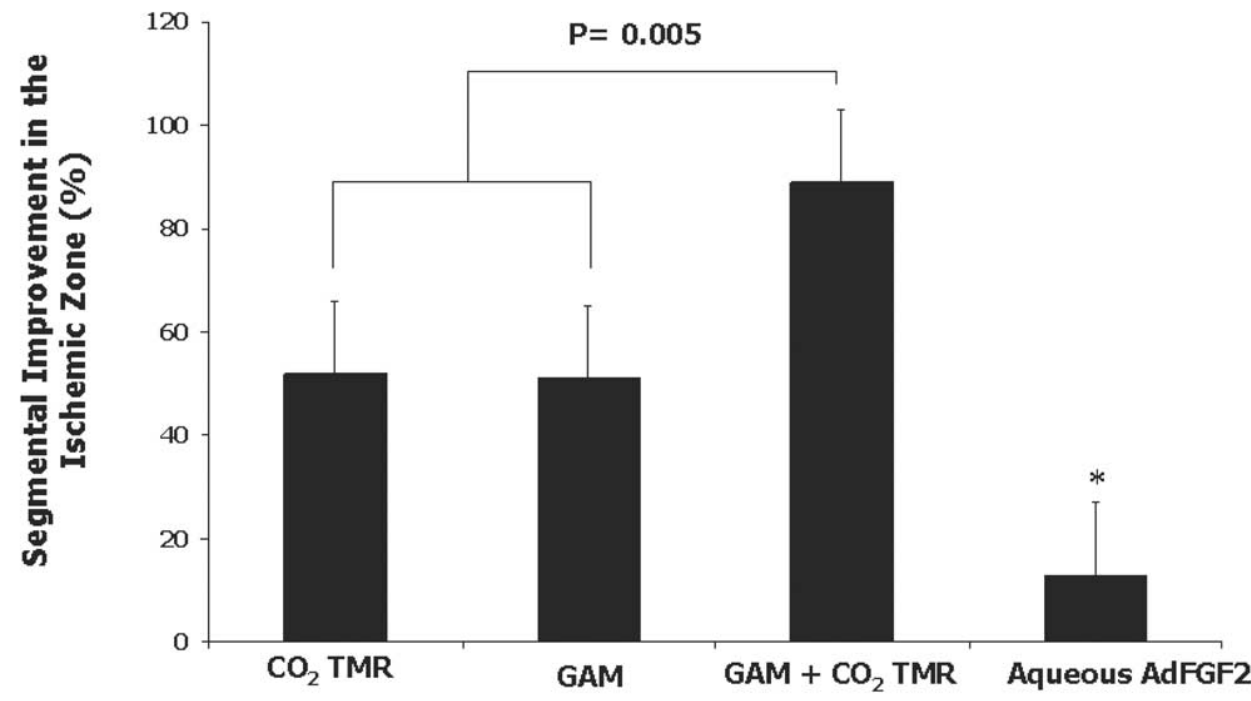

\section{Treatment Groups}

Figure 2. Contractility as assessed by cine magnetic resonance imaging (MRI). The percentage of improved cine MRI segments were calculated. The matrix AdFGF2 $+\mathrm{CO}_{2}$ TMR-treated group demonstrated the most significant improvement compared with the other groups. ${ }^{*} P<.05$ aqueous AdFGF2 versus all other groups.) 


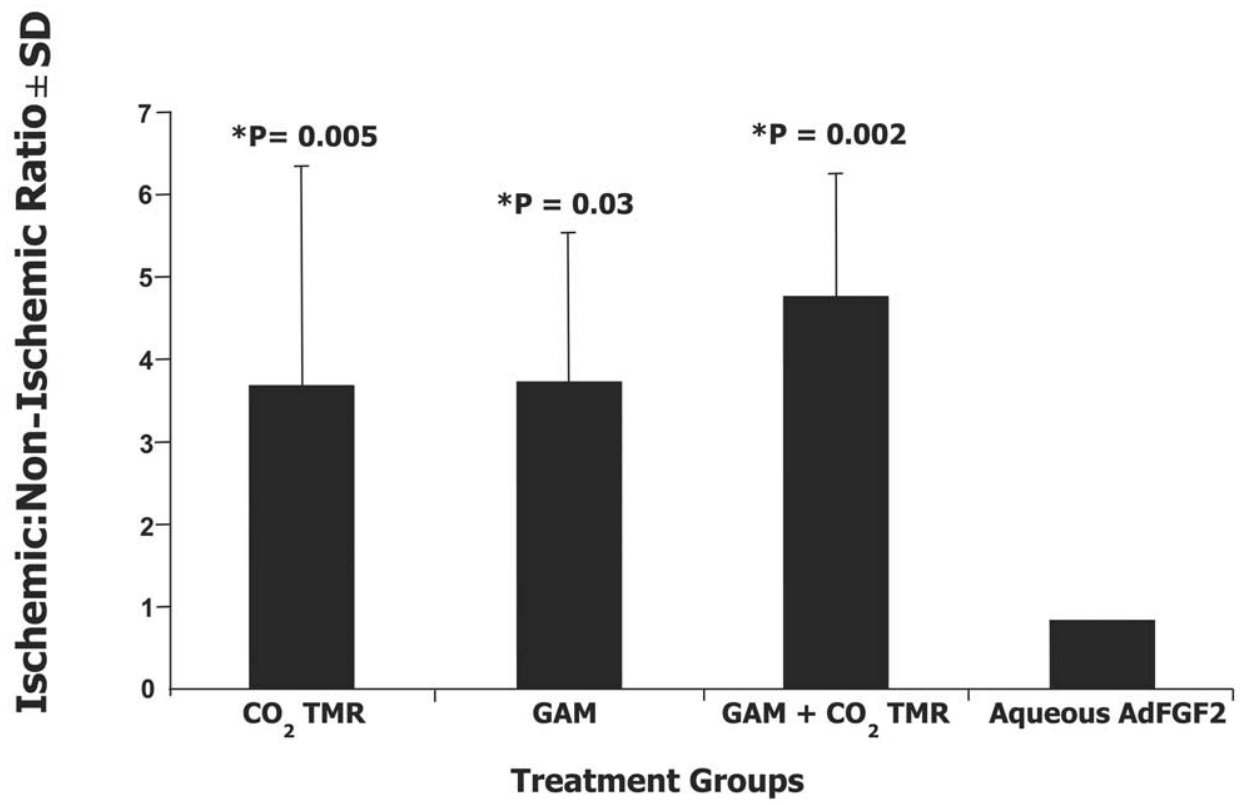

Figure 3. Arteriolar development. The degree of angiogenesis is quantified by the arteriole area ratio between ischemic and nonischemic zones of each animal. As shown, matrix AdFGF2 + $\mathrm{CO}_{2}$ TMR-treated areas had a $27 \%$ increase in arteriole area versus either treatment alone and a $470 \%$ increase compared with saline-formulated AdFGF2 treatment. (*P value vs aqueous AdFGF2.)

(6\%) showed improvement after treatment with salineformulated AdFGF2. On the basis of previous work using this same animal model and cine MRI analysis, only 12 of the 216 segments $(6 \%)$ in an untreated controlled group typically show any improvement in function. ${ }^{11}$ The nonischemic segments for each group showed no change in function. Contrast-enhanced MRI results revealed no evidence of myocardial infarction for any segments.

Histologic assessment confirmed no evidence of significant infarctions as noted on hematoxylin-eosin or Mallory's trichrome staining. Although neovascularization was noted at treatment sites in all groups, vessel density and maturity were much more pronounced in the TMR- and/or GAM-treated groups compared with the saline-formulated AdFGF2 group (Figure 3). In particular, GAM-treated sites (with or without concomitant TMR) revealed a high density of muscular walled arterioles (as demonstrated by anti- $\alpha$ actin staining). The arteriolar wall area of the ischemic zone was compared in a ratio with the arteriolar area of the nonischemic zone for each treatment group. This measure of arteriogenesis was greatest for the animals treated with GAM $+\mathrm{CO}_{2}$ TMR. Because of the range of the results yielding broad standard deviations, there were no significant differences between the $\mathrm{CO}_{2}$ TMR combination treatment and animals treated with either GAM or $\mathrm{CO}_{2}$ TMR alone. There was, however, a statistically significant difference between those treatments and the group that was treated with the saline-formulated form of the AdFGF2. As expected, there was no difference in the nonischemic area between these 2 groups $(5 \%)$.

Representative sections from the ischemic zone of each group are presented in Figure 4. A robust neovascularization response, marked by numerous muscular arterioles, was seen in animals treated with $\mathrm{CO}_{2} \mathrm{TMR}$, matrix-formulated AdFGF2, and the combination of both. The most striking feature of this response was both a greater number and a greater size of these vessels of muscular-walled vessels than that observed in saline-formulated AdFGF2.

\section{Discussion}

The natural response to myocardial ischemia resulting from coronary artery disease is neovascularization. This angiogenic process is a physiologic attempt to limit myocardial ischemia; however, despite this goal it may fail to provide adequate perfusion and restoration of function to the ischemic myocardium. In an attempt to improve on this process, mechanical and pharmacologic stimulation of additional angiogenesis have been tried. Such means of increasing angiogenesis include TMR and the delivery of angiogenic growth factors (as either recombinant proteins or geneencoding vectors). We previously demonstrated that both these modalities can stimulate angiogenesis, increase perfusion, and restore myocardial function. Despite favorably preclinical results with angiogenic growth factors such as 


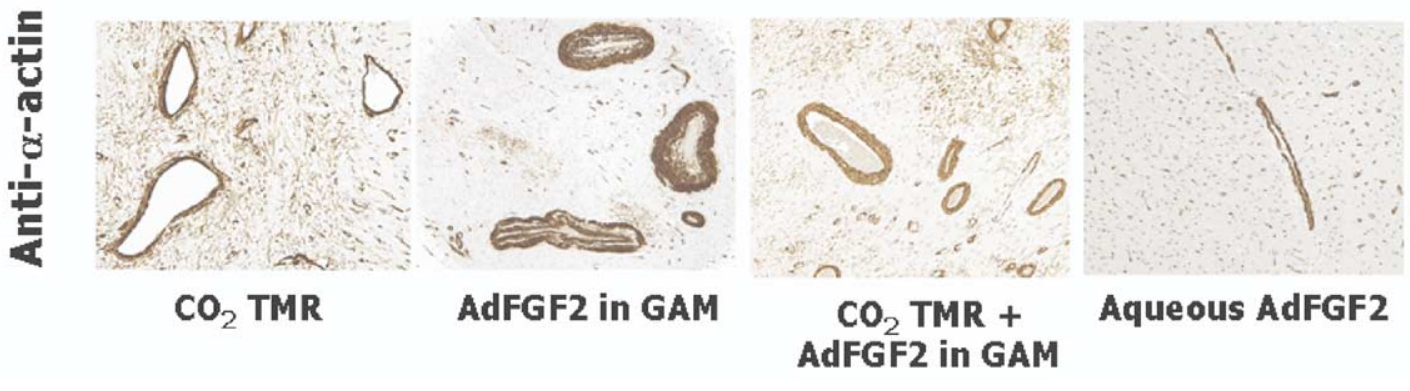

Figure 4. Neovascularization after gene therapy and TMR treatment. Representative histologic images taken from the ischemic zones after treatment. Notice the enhanced vascular development, as marked by the numerous muscular arterioles, in $\mathrm{CO}_{2}$ TMR/AdFGF2 in gene-activated matrix (GAM) groups compared with the salineformulated AdFGF2 group.

vascular endothelial growth factor, FGF1, and FGF2, however, clinical responses are limited. ${ }^{9}$ The key limitation of growth factor protein therapy seems to be difficulty in achieving sustained therapeutic protein concentrations at the intended sites.

On the basis of this past experience, we reasoned that a combined application of $\mathrm{CO}_{2}$ TMR plus angiogenic gene delivery might induce an additive level of neovascularization adequate for achieving the ultimate goal of such therapies, namely, improved left ventricular functioning. For these therapies to achieve the maximal possible additive benefit, we also reasoned that gene vectors should be delivered directly into TMR channels, rather than at adjacent sites. The traditional gene therapy approach of delivering aqueous-formulated gene vectors, however, is unlikely to yield meaningful retention within TMR channels. Matriximmobilized vectors, or GAMs, on the other hand, are ideally suited for both direct application to and retention at wound sites, ${ }^{30,31}$ and therefore we devised a treatment strategy in which laser TMR would first be applied to the ischemic myocardial territory, followed immediately by direct injection of GAM into the TMR channels. For a GAM, we selected an adenovirus encoding FGF2 formulated in a collagen/gelatin admixture, based on its previous successful use to induce arteriogenesis in skeletal muscle wounds. ${ }^{30}$ Induction of higher caliber vessels, such as muscular arterioles, is likely the best pattern of neovascularization for ischemic tissues, in that arterioles allow for greater blood inflow compared with microvasculature and muscularwalled vessels provide the potential for vasoregulation.

In agreement with our previous studies, ${ }^{11,30}$ collagenimmobilized AdFGF2 induced a significantly greater arteriogenic response in treated tissue compared with salineformulated vector. In the earlier studies, we were able to attribute this difference to a greater retention of AdFGF2 at delivery sites by the matrix formulation. We suggest that a similar situation also occurred in the present work, and furthermore that the data presented now demonstrate the value of enhanced arteriogenesis, namely, an improvement in myocardial functional recovery as assessed by both echocardiography and cine MRI.

Not surprisingly, on the basis of previous studies, we observed an enhanced arteriogenic response and restoration of myocardial function with the combination of $\mathrm{CO}_{2}$ TMR and GAM AdFGF2. This reached significance for the chosen end points, including functional improvement as assessed by echocardiography and MRI, as well as histologic analysis of arteriolar development. The establishment of this significant arteriogenesis is critical because its induction provides the significant perfusion to reverse myocardial ischemia. In addition, the histologic analysis confirms that the matrix-formulated vectors are present in the TMR channels posttreatment. Furthermore, this arteriogenesis is enhanced in the TMR-treated areas, more significantly than TMR or GAM treatment alone.

Contrast-enhanced MRI results also demonstrated no evidence of myocardial infarction for any of the segments. This was also confirmed by histologic assessment.

These results indicate that the combination of GAM AdFGF2 plus $\mathrm{CO}_{2}$ TMR provides a salutary angiogenic response that has significant clinical implications and in planned translational work may provide a better treatment in combination than either therapy alone.

\section{References}

1. Giordano FJ, Ping P, McKirnan MD, Nozaki S, DeMaria AN, Dillmann WH, et al. Intracoronary gene transfer of fibroblast growth factor-5 increases blood flow and contractile function in an ischemic region of the heart. Nat Med. 1996;2:534-9.

2. Tio RA, Tkebuchava T, Scheuermann TH, Lebherz C, Magner M, Kearny $\mathrm{M}$, et al. Intramyocardial gene therapy with naked DNA encoding vascular endothelial growth factor improves collateral flow to ischemic myocardium. Hum Gene Ther. 1999;10:2953-60.

3. Lee LY, Patel SR, Hackett NR, Mack CA, Polce DR, El-Sawy T, et al. Focal angiogen therapy using intramyocardial delivery of an adenovi- 
rus vector coding for vascular endothelial growth factor 121. Ann Thorac Surg. 2000;69:14-24.

4. Rosengart TK, Lee LY, Patel SR, Sanborn TA, Parikh M, Bergman $\mathrm{GW}$, et al. Angiogenesis gene therapy: phase I assessment of direct intramyocardial administration of an adenovirus vector expressing VEGF121 cDNA to individuals with clinically significant severe coronary artery disease. Circulation. 1999;100:468-74.

5. Symes JF, Losordo DW, Vale PR, Lathi KG, Esakof DD, Mayskity M, et al. Gene therapy with vascular endothelial growth factor for inoperable coronary artery disease. Ann Thorac Surg. 1999;68:830-6.

6. Vale PR, Losordo DW, Milliken CE, Maysky M, Esakof DD, Symes $\mathrm{JF}$, et al. Left ventricular electromechanical mapping to assess efficacy of phVEGF ${ }_{165}$ gene transfer for therapeutic angiogenesis in chronic myocardial ischemia. Circulation. 2000;102:965-74.

7. Epstein SE, Fuchs S, Zhou YF, Baffour R, Kornowski R. Therapeutic interventions for enhancing collateral development by administration of growth factors: basic principles, early results and potential hazards. Cardiovasc Res. 2001;49:532-42.

8. Laham RJ, Sellke FW, Edelman ER, Pearlman JD, Ware JA, Brown DL, et al. Local perivascular delivery of basic fibroblast growth factor in patients undergoing coronary bypass surgery: results of a phase I randomized, double-blind, placebo-controlled trial. Circulation. 1999; 100:1865-71.

9. Simons M, Bonow RO, Chronos NA, Cohen DJ, Giordano FJ, Hammond $\mathrm{K}$, et al. Clinical trials in coronary angiogenesis: issues, problems, consensus: an expert panel summary. Circulation. 2000;102: e73-e86.

10. Henry TD, Annex BH, Azrin MA. Final results of the VIVA trial of rhVEGF human therapeutic angiogenesis. Circulation. 1999(Suppl); 100:I476.

11. Horvath KA, Doukas J, Lu CJ, Belkind N, Greene R, Pierce GF, et al. Myocardial functional recovery after fibroblast growth factor 2 gene therapy as assessed by echocardiography and magnetic resonance imaging. Ann Thorac Surg. 2002;74:481-7.

12. Cooley DA, Frazier OH, Kadipasaoglu KA, Lindenmeir MH, Pehlivanoglu S, Kolff JW, et al. Transmyocardial laser revascularization: clinical experience with twelve-month follow-up. J Thorac Cardiovasc Surg. 1996;111:791-9.

13. Horvath KA, Mannting F, Cummings N, Sherman SK, Cohn LH. Transmyocardial laser revascularization: operative techniques and clinical results at two years. J Thorac Cardiovasc Surg. 1996;111: 1047-53.

14. Horvath KA, Cohn LH, Cooley DA, Crew JR, Frazier OH, Griffith BP, et al. Transmyocardial laser revascularization: results of a multicenter trial with transmyocardial laser revascularization used as sole therapy for end-stage coronary artery disease. J Thorac Cardiovasc Surg. 1997; 113:645-54.

15. Burkhoff D, Schmidt S, Schulman SP, Myers J, Resar J, Becker LC, et al for the ATLANTIC Investigators. Transmyocardial laser revascularization compared with continued medical therapy for treatment of refractory angina pectoris: a prospective randomized trial. Lancet. 1999;354:885-90.

16. Frazier $\mathrm{OH}$, March RJ, Horvath KA. Transmyocardial revascularization with a carbon dioxide laser in patients with end-stage coronary artery disease. N Engl J Med. 1999;341:1021-8.

17. Schofield PM, Sharples LD, Caine N, Burns S, Tait S, Wistow T, et al. Transmyocardial laser revascularization in patients with refractory angina: a randomized controlled trial. Lancet. 1999;353:519-24.

18. Allen KB, Dowling RD, Fudge TL, Schoettle GP, Selinger SL, Gangahar DM, et al. Comparison of transmyocardial revascularization with medical therapy in patients with refractory angina. $N$ Engl J Med. 1999;341:1029-36.
19. Horvath KA, Aranki SF, Cohn LH, March RJ, Frazier OH, Kadipasaoglu KA, et al. Sustained angina relief 5 years after transmyocardial laser revascularization with $\mathrm{aCO}_{2}$ laser. Circulation. 2001;104:181-4.

20. Spertus JA, Jones PG, Coen M, Garg M, Bliven B, O'Keefe J, et al. Transmyocardial $\mathrm{CO}_{2}$ laser revascularization improves symptoms, function, and quality of life: 12-month results from a randomized controlled trial. Am J Med. 2001;111:341-8.

21. Spanier T, Smith CR, Burkhoff D. Angiogenesis: a possible mechanism underlying the clinical benefits of transmyocardial laser revascularization. J Clin Laser Med Surg. 1997;15:269-73.

22. Yamamoto N, Kohmoto T, Gu A, DeRosa C, Smith CR, Burkhoff D. Angiogenesis is enhanced in ischemic canine myocardium by transmyocardial laser revascularization. J Am Coll Cardiol. 1998;31: 1426-33.

23. Burkhoff D, Fisher PE, Apfelbaum M, Kohmoto T, DeRosa CM, Smith CR. Histologic appearance of transmyocardial laser channels after 41/2 weeks. Ann Thorac Surg. 1996;61:1532-35.

24. Mirhoseini M, Shelgikar S, Cayton M. Clinical and histological evaluation of laser myocardial revascularization. J Clin Laser Med Surg. 1990;8:73-7.

25. Horvath KA, Smith WJ, Laurence RG, Schoen FJ, Appleyard RF, Cohn LH. Recovery and viability of an acute myocardial infarct after transmyocardial laser revascularization. J Am Coll Cardiol. 1995;25: 258-63.

26. Horvath KA, Chiu E, Maun DC, Lomasney JW, Greene R, Pearce $\mathrm{WH}$, et al. Up-regulation of VEGF mRNA and angiogenesis after transmyocardial laser revascularization. Ann Thorac Surg. 1999;68: $825-9$.

27. Li W, Chiba Y, Kimura T, Morioka K, Uesaka T, Ihaya A, et al. Transmyocardial laser revascularization induced angiogenesis correlated with the expression of matrix metalloproteinases and plateletderived endothelial cell growth factor. Eur J Cardiothorac Surg. 2001;19:156-63.

28. Lutter G, Attmann T, Heilmann C, von Samson P, von Specht B, Beyersdorf $\mathrm{F}$. The combined use of transmyocardial laser revascularization (TMLR) and fibroblastic growth factor (FGF-2) enhances perfusion and regional contractility in chronically ischemic porcine hearts. Eur J Cardiothorac Surg. 2002;5:753-61.

29. Heilmann CA, Attmann T, von Samson P, Gobel H, Marme D, Beyersdo Lutter G. Transmyocardial laser revascularization combined with vascular endothelial growth factor 121 (VEGF121) gene therapy for chromyocardial ischemia — do the effects really add up? Eur J Cardiothorac Surg. 2003;23:74-80.

30. Doukas J, Blease K, Craig D, Ma C, Chandler LA, Sosnowski BA, et al. Delivery of FGF genes to wound repair cells enhances arteriogenesis and myogenesis in skeletal muscle. Mol Ther. 2002;5:517-27.

31. Doukas J, Chandler LA, Gonzalez AM, Gu D, Hoganson DK, Ma C, et al. Matrix immobilization enhances the tissue repair activity of growth factor gene therapy vectors. Hum Gene Ther. 2001;12:783-98.

32. Horvath KA, Greene R, Belkind N, Kane B, McPherson D, Fullerton DA. Left ventricular functional improvement after transmyocardial laser revascularization. Ann Thorac Surg. 1998;66:721-25.

33. Chad HG, Post MJ, Simons M, Annex BH. Translational physiology: porcine models of human coronary artery disease: implications for preclinical trails of therapeutic angiogenesis. J Appl Physiol. 2003;94: 1689-701.

34. O'Konski MS, White FC, Longhurst J, Roth D, Bloor CM. Ameroid constriction of the proximal left circumflex coronary artery in swine. A model of limited coronary collateral circulation. Am J Cardiovasc Pathol. 1987;1:69-77. 